\title{
Juggling Work and Family Demands: Lifestyle Career Anchors for Female Healthcare Professionals
}

\author{
Dr Margaret J Nowak \\ Curtin Graduate School of Business \\ Perth, Western Australia \\ and \\ Dr Dede Bonner \\ Curtin Graduate School of Business \\ Perth, Western Australia
}

Corresponding author:

Dr Margaret J Nowak

Curtin Graduate School of Business

78 Murray St

Perth WA 6000

Australia

Email: Margaret.Nowak@gsb.curtin.edu.au (can be published)

Phone: $61+8+93108370$

Word count for text only: 4871

Tables: 2 


\section{Professor Margaret J Nowak}

BEc (Hons)(Syd), MEd(Syd), GradDipEd(WAIT), PhD(Murdoch), FAICD

Professor Margaret Nowak is an economist and Professor with Curtin Graduate School of Business, Perth. Margaret's research interests have focused on labour markets and on corporate governance. In recent years Margaret has done research on the nursing labour market and has undertaken a number of consultancies on issues related to the nursing workforce for the School of Nursing, Curtin, and the Health Department of WA. In 2001-2003 Margaret was the research leader for an ARC funded research program on the nursing labour market titled 'Women and their changing work and family roles - implications for occupational choice and workforce participation decisions'.. In the field of Corporate Governance Margaret has undertaken research on information issues in accountability, shareholder activism and governance, comparative governance and corporate social responsibility. She has been involved in two submissions to The Joint Parliamentary Committee, Corporations and Markets, Commonwealth of Australia.

Margaret chaired the Nursing Career Structure Evaluation Committee, Department of Health, in 1989/90 and was a member of the Steering Committee. New Vision, New Direction, Study for the future of nursing and midwifery in Western Australia. She was a WHO Temporary Advisor for the 'Consultation on imbalances in the health workforce', Ottawa 2002.

\section{Dr Dede Bonner}

Dr Bonner holds an Ed D. (George Washington University), MA (Marymount ) and BEd (Michigan State University) She is an Adjunct Professor with Curtin Graduate School of Business, Perth, and teaches at Marymount University, Virginia. Dr Bonner is Principal of New Century Management which undertakes management consulting at the highest levels in Government and Defense. Dr Bonner has held positions as editorial chair and Board member of the American Society for Training and Development (ASTD) .

Dr Bonner has written and presented extensively on Career Development, Career Anchors, Performance Improvement, Knowledge Management, Downsizing and Careers, Questioning Skills and Critical Thinking.

Juggling Work and Family Demands: Lifestyle Career Anchors for Female Healthcare Professionals

\section{Abstract}


The well-established construct of Schein's career anchors provides our theoretical framework for understanding the career motivations, values and goals of women healthcare professionals in Western Australia. ${ }^{1,2,3}$ As part of their response to questions put to them while on they were on paid maternity leave, the subjects reflected on returning to work full-time, changing jobs or careers, working part-time or total career discontinuity in favor of family needs. Schein's career anchor of 'Lifestyle' guides our exploration into the workforce involvement and career orientations of these 388 subjects. The healthcare industry is one where female professionals predominate, and nurses in particular represent a profession for which it is often difficult to attract top young talent and retain experienced mid-career professionals. We found that although the majority of our subjects believed they had sacrificed some aspects of their personal career and educational goals after their children were born, most were still strongly attracted to their careers and would actively seek self-initiated or employer-sponsored solutions to help achieve a satisfying balance of work and family priorities.

\section{Keywords : Career Anchors, Lifestyle Anchor, Careers of Female Healthcare Professionals Acknowledgements}

The authors wish to acknowledge the assistance provided by the Health Department of Western Australia and St John of God Healthcare (WA) in accessing staff on maternity leave.

\section{Conflict-of-interest}

The authors have no conflicts-of-interest in regard to this research or its publication.

\section{Introduction}


Women now represent approximately 50 percent of higher education graduates and approximately half of new entrants into professional occupations in OECD countries. We know that newly graduated women commence their careers strongly motivated and committed to career development. ${ }^{4,5}$ But for many working women, including healthcare professionals, the mid-career point of their lives - the time when they are most likely to be highly motivated towards growth opportunities within their profession and/or organization - coincides with their prime childbearing years. Many female employees are forced to make hard choices while they are caring for young children.

The career orientations of women have been investigated in depth for the past forty years, including more than one hundred studies utilizing Schein's gender-neutral Career Orientations Inventory which is based on his theory of "career anchors." $1,3,6$ Despite evidence that for graduates there are many similarities between men and women's career goals, ${ }^{7,8}$ women who have children experience a significant lifetime earnings deficit relative to their counterparts with no children. ${ }^{9-12}$ While there is a range of factors which contribute to this including employment breaks, reduced working hours, and levels of experience, there is evidence that the birth of a child results in many women moving to a different career trajectory that includes settling for plateaued career advancement, reduced income, and in some cases less job satisfaction. ${ }^{13,14}$

\section{Literature Review}

The career anchor concept represents a unique synthesis of an individual's self-perceived image, career motivations, values, and actual work experiences. Edgar Schein suggests that the life 
experiences that people undergo give them an increasingly accurate and stable 'career-selfconcept,' which identifies as their 'career anchor. ${ }^{1,15,16}$ Central to Schein's work is a fundamental questioning of how and why individuals make career decisions. He conducted a longitudinal study from 1961 to 1973 in which he assessed the career motivations, educational and occupational histories, work values, work attitudes, future plans, ambitions, values, and selfconcepts of 44 randomly selected Master of Business Administration (MBA) students.

The result was the development of Schein's theory of career anchors, which he defines as 'a motivational/attitudinal/value syndrome that guides and constrains the person's career.' ${ }^{15} \mathrm{~A}$ career anchor is a 'descriptive and predicative tool' that is 'inside the person, functioning as a set of driving and constraining forces on career decisions and choices'. ${ }^{1}$ A career anchor has three components:

(1) self-perceived talent and abilities;

(2) self-perceived motives and needs; and

(3) self-perceived concepts, attitudes and values.

The first two components are based on actual experience in a work setting, while the third is derived from the individual's reaction to a variety of norms and values encountered in different social and work situations. Schein regards a career anchor as 'That one element in a person's self-concept, which he or she will not give up, even in the face of difficult choices' ${ }^{6}$ Schein posits that individuals' future career choices are affected as they mature and their anchor stabilizes. $^{6}$ 
From his initial longitudinal study, Schein concluded that there are these five career anchors:

1. Technical/Functional Competence (overwhelming drive for expert status among peers)

2. General Managerial Competence (desire to solve complex, whole-organization/system problems)

3. Autonomy (strongest need is freedom of personal choices for job tasks and settings)

4. Security/Stability (overriding need to work for an organization offering long-term benefits and solid retirement plans)

5. Entrepreneurial Creativity (motivated to seek innovative or start-up businesses, products or services).

Subsequent research discovered three additional career anchors:

6. Service/Dedication to a Cause (overwhelming desire to work for lofty goals or in a humanitarian capacity)

7. Pure Challenge (self-fulfillment by testing one's personal endurance and/or physical limits)

8. Lifestyle (striving to maintain a healthy balance between work demands and one's children's/family's wellbeing). ${ }^{6,17-19}$

Schein's basic typology has held firm despite forty years of major shifts in the workplace, fundamental changes in career expectations, hundreds of researchers seeking to refute his career anchors theory, and widespread, popular use of his theory-based Career Orientations Inventory. ${ }^{6}$ For example, widely diverse career anchor studies have investigated career issues for single 
professions, ${ }^{20-24}$ organizational concepts, ${ }^{25,26}$ gender-focused studies, ${ }^{27,28}$ multi-national or national populations, ${ }^{29,30}$ and numerous research methodologies.

Most organisations base their employee rewards and career development systems on the faulty assumption that all employees are equally motivated by the prospect of a promotion. ${ }^{31}$ Therefore, the majority of previous studies are focused on relating career anchors to the external side of career, including career paths, ladders and/or education programs. A significant gap exists in our understanding individuals' internal career motivators. This is especially true for women in the workforce. ${ }^{27,28,32}$

To date, a total of thirteen career anchor studies have specifically investigated women's careers. However, these previous gender-based studies have not yielded clear patterns of career anchor differences. For example, Konrad et al. concluded that women in their study were more likely to be aligned with lifestyle and challenge career anchors as compared to men who showed a preference for the security/stability anchor. ${ }^{33}$ Pelos found that one of the most common reasons women entered entrepreneurship was to achieve a satisfying balance of family and work demands, but found no significant gender-based differences in comparison to all-male populations. $^{28}$

\section{Methodology and data collection}

This research forms part of a larger study which explored the experiences and decisions of women in health professions who had taken paid maternity leave. Data collection was undertaken between June and September 2010. One public health system provider and one 
nationally based private sector hospital healthcare provider facilitated the study by sending the questionnaire to all women in designated health professional occupations who were currently on their payroll records as on maternity leave, part of which was entitlement to paid leave. Health professional was defined as all nurses, medical doctors, physiotherapists, occupational and speech therapists, psychologists, social workers, pharmacists, dieticians and medical imagers. We received 340 responses from the public provider, a response rate of $37 \%$ and 48 responses from staff of the private provider, a response rate of $31 \%$.

The focus on lifestyle issues was provided in questions about the impact of family issues on choice of profession and the trade-off made between family and career. To facilitate the collection of rich nuanced data for exploring the varied individual situations and decision making these questions allowed the respondent to specify issues and elaborate on responses. Data from responses to open ended questions were managed using NVivo software. The study population did not complete Schein's Career Anchors Inventory.

Qualitative data were analyzed using the framework of Schein's Lifestyle anchor Inventory questions. In the analysis below we first provide a thumbnail picture of the women in the study. We then consider the rich data provided by them explaining their decisions and the issues for them.

\section{Demographics and work experience}

Of the 388 respondents, 243 were in nursing including midwifery, 31 were medical doctors and 114 were Allied Health and other health professionals. Only 12\% of respondents were aged 29 
or less; over $75 \%$ were between 30 and 39 years of age. These data confirm the trend for women to have their families later. Australian data show that in 2008 42\% of women who had their first child were aged 30 years and over, up from $33 \%$ in $1998 .{ }^{34}$ The professional women in this study were generally older than the median age for the birth of the first child.

These women were well experienced professionals, likely to have occupied mid-career level positions and be at a pivotal point in their career development. The mean number of years that the respondents had practiced their profession was 10.7. Of respondents, 191 reported that they were in full-time work and 190 in part-time work prior to their current maternity leave. Mean hours per week for those working part-time was 21.5 and the mean number of years of part-time work 2.7. While half of the respondents had been in full-time work prior to their current maternity leave, only $5 \%$ indicated that they would return to a full-time position. Of the remainder returning to work, $45 \%$ indicated they would return to a part-time position with shifts/on-call and $43 \%$ to part-time work involving no shifts or on-call. Just over $60 \%$ of those returning to part-time work expected to work for between 15 and 24 hours per week.

These women were overwhelmingly either married or in a relationship. Only $1.8 \%$ were neither married nor in a relationship; a further 1.5\% indicated that their spouse was not present. Most respondents (85\%) had either one or two children. For almost 50\% this was their first. Most respondents expected to return to work after between one and two years of leave. 
While the respondents strongly supported a view that women today have more career options than their mothers, these women also strongly held the view that the workplace did not provide equal opportunities and that women's' promotional prospects were not the same as for men.

Our respondents were on maternity leave and considering their options for the return to work. Around half had experienced this state before and thus had understanding of the issues in their workplace while the rest were new mothers. These women were experienced health professionals, many of whom had achieved career progression and would be characterized as being in early to mid career. Their expectations generally were that it would be difficult to combine career and motherhood and less than $20 \%$ considered that men and women had equal opportunities in the workforce. Overall these professional women do perceive that women face very considerable difficulties in combining family and career and a playing field which is a long way yet from appearing level.

\section{Lifestyle career Anchor}

Based on the premise that there's a rapid rise of the Lifestyle career anchor in the workplace, ${ }^{3,29}$ and the proven relevance of Lifestyle anchors for women, ${ }^{28,33,35}$ we looked at the emerging themes around the Lifestyle anchor in our data.

We focus on the Lifestyle career anchor as a mechanism to better understand the issues women healthcare professionals face as they juggle career demands with family needs. Individuals with a predominant Lifestyle career anchor are highly concerned with issues such as maternity/ 
paternity leave, childcare options, part-time versus full-time work schedules, and alternative work opportunities, including working from home.

We sought to answer: " How do healthcare professionals address their own experiences within this career/life concept in an increasingly complex and demanding work environment?" The lifestyle anchor emphasizes the importance of the successful balance of personal and professional lives. Households containing dual career families experience the complexities of balancing financial, geographical, and related lifestyle decisions. ${ }^{3}$ Women facing the birth of children typically face new economic uncertainties and increasing demands on their time and monetary resources.

Because the healthcare industry, especially the nursing field, is predominately female, understanding their career motivations is especially relevant. Aune in her qualitative study of the career anchors of nurses discovered strong evidence for the existence of the lifestyle career anchor even before it had been formally identified and named by Schein and others in the 1990s. ${ }^{20}$ For example, a nursing assistant states, "This organization just has to understand that I cannot sacrifice my weekends with my husband to be here or to attend Saturday meetings and workshops routinely. I'm committed to my job and my profession, but I'm also committed to my relationship with my husband and to being a person". A nurse says, "Sure, I wanted marriage and a family, but I wanted more, too. I wanted it all." Although an early indication of the existence of a Service/Dedication to a Cause career anchor was Aune's major finding, she also concluded: 'All of the groups emphasized relationships as most important in their lives, and 
though these nurses wanted their careers, most indicated that their relationships would be the last thing they would want to lose.'

Similarly, McLees' study of the career patterns of nurses found that although the Lifestyle career anchor was still not distinctively defined, 'being able to maintain a balance between my profession and my family and friends is important to me,' has the highest mean score for both nurses (3.83) and other health professionals (3.96) in the study (p. 89). ${ }^{21}$ In addition, McLees found a strong negative correlation between ambition for leadership and family commitment (0.31). Jackle concluded that the highest career anchors of the contingent nurses in her study were altruism (service), independence, and family commitment. ${ }^{36}$

Kaplan et. al compared young nurses who had recently undertaken 4 year academic programs with a cohort of second career nurses who had undertaken intensive training at a later age. ${ }^{24}$ They found that for second career nurses specialization and lifestyle were the predominant career anchors whereas the younger graduates chose management, autonomy and service. The finding is consistent with Schein's position on career anchors changing and stabilizing with experience. ${ }^{6}$

\section{Lifestyle Inventory Questions and the Study Data}

Schein's Career Orientations Inventory includes five questions that are targeted to the Lifestyle career anchor. ${ }^{6}$ We found a strong correlation between our participants' comments and these Lifestyle inventory questions as follows. 
I would rather leave my organization than be placed in a job that would compromise my ability to pursue personal and family concerns. (Question 8)

- A woman/mother has to choose between her career and her family even in today's age. One cannot have it all and it is naive of women to think they can. More importantly a woman must be happy with the choices she has made to be an effective mother and have a satisfying career. This involves talking and researching your career and working out and possibly adapting your priorities as life goes on.

- I have put my career on hold. It comes second to my family's happiness. I am happy with this decision as I can pick up work later.

- Family is more important. Work has taken a back seat compared to before children. It is more a financial means than my being career orientated.

- From being a career driven person after becoming a parent I have reviewed my values and chosen to be with my child full time to the present.

- My family life is more important than my career. I am happy working to gain an income but currently retraining to do a more family friendly job.

I dream of a career that will permit me to integrate my personal, family, and work needs. (Question 16)

- It is impossible to do both without trade-offs. Time at work is time away from family and vice-versa.

- It is really difficult to juggle all the hats of mother, wife, friend, employee etc. Returning to work will affect my individual personal time and my ability to have time to exercise. 
- I don't want to work with a little child because it isn't fair on her. I wouldn't bother but I have to because of financial reasons. I also want to be home every night for a breastfeed before she goes to sleep but I sometimes can't because of my shifts.

- It is really difficult to juggle all the hats of mother, wife, friend, employee etc. Returning to work will affect my individual personal time and my ability to have time to exercise.

- Until I returned to work the first time after maternity leave I didn't realise how difficult it is to return to work and balance family life. Comments such as "Oh you only work 2 days a week" are innocent but show that people do not acknowledge your other responsibilities. I guess sometimes I feel guilty I can’t do more shifts for my work place who are always short staffed but also undervalued, I still have the same skills/knowledge, I'm just not there as much as I used to be.

I feel successful in my life only if I have been able to balance my personal, family, and career requirements. (Question 24)

- My career is stagnated, I've had to return to ward-based shift work and give up my previous position of SON on the ward. Unless you work full-time there are no positions to aspire to.

- I will no longer be able to participate in complex cases that will further my career but rather I will be relegated to simple, non-complex cases that are not challenging or career enhancing.

- Male contemporaries are now consultants, but would be much more devastated never to be a mum than never to be a consultant. 
- It's difficult, have worked for over a decade to achieve my professional status and feel disappointed that my 'value' to the medical community will go down. Part- time workers are necessary in my profession for simple, non-complex work, but are generally not well respected. Do have a beautiful baby as compensation though.

Here the women reflect on their inability to achieve the lifestyle balance they sought when they made their career choice. Table 1 below indicates that $60 \%$ of the women in our study saw ability to combine career and family as a consideration in their career choice, while the expectation of other family friendly related job conditions also played major roles in that decision.

\section{Table 1}

Balancing the demands of personal and professional life is more important to me than achieving a high level managerial position. (Question 32)

- My career is taking a back seat. I am missing out on PD; peers who graduated with me are already in higher positions.

- Had I continued to work full time I feel I could expect to advance into management in the near future, however I only wish to work part-time until my children are older which appears to often not be compatible with management positions.

- I have not applied for promotion opportunities due to working part-time and maternity leave. The last position to come up I was the prime candidate as I had more experience than all the other staff in department but didn't apply due to above reasons. 
- I could have gone higher up the career ladder or pursued a career in health promotion but having a child kept me out of the field, I lost my skills and confidence and I never returned to health promotion

- If I had not decided to have children I would have applied for a full-time permanent position as soon as one came up and would likely be more knowledgeable in my field and maybe better paid,...

- I was going to choose a high stress type of medical career (cardiology) but chose quieter/ less stressful gerontology so could pursue family life easier.

- Being a stay at home mum is my current job, nursing will have to wait and yes I have missed out on career development but am happy with my choice.

The comments are consistent with the quantitative data from the study. As Table 2 below shows, while over $38 \%$ of these women say that they are career motivated, virtually all these women indicated that time with family was more important than promotion at the time of their response.

\section{Table 2}

Such responses are, to a degree, influenced by the particular situation of the respondent in their work-life-cycle. A recent study of nurses 1 to 3 years following graduation found that $58 \%$ either agreed or strongly agreed they were career motivated. ${ }^{4}$

\section{Discussion}

The picture which emerges from the responses of these women contemplating their work participation and career following a period of maternity leave is highly consistent with Schein's Lifestyle career anchor. These women have an ongoing commitment to employment and career 
but this commitment will be in the context of 'enabling' workplace conditions which support their broader lifestyle requirements based around family and personal values.

\section{Related Emerging Themes}

We found several emerging sub-themes that we believe are also relevant to this discussion. While some of these may be merely wording nuances, we also believe the following themes and comments enrich the discussion of the importance of Lifestyle balance for women in the workforce. The sub-themes follow:

\section{This was my choice.}

Study participants noted that they had made clear, well-informed decisions when planning the sequence and timing of their careers and children. Illustrative comments include:

- Being a stay at home mum is my current job, nursing will have to wait and yes I have missed out on career development but am happy with my choice.

- I have waited until fully qualified as a specialist before becoming a mother -easier to work part time and easier to be a consultant rather than registrar; I am not working exactly my ideal job however.

- I chose not to have children until I was at a point in my career where I was fulfilled professionally and now am enjoying the change.

2. My work ambitions are permanently diminished as a result of having children. 
Some participants believed that even after they returned to work from maternity leave, their careers would be permanently stalled. They seemed resigned to settle for less career advancement and/or satisfaction in comparison to previous self-perceived career aspirations.

- Having children has affected my career as I can't work full-time and skills are diminished over time hence you are given less complex patients to care for and the cycle continues.

- I will probably not return to full-time work for 10 years if ever. This means I will not further my career in the same way I would if I didn't have a family.

- Thought I would return to work but since having my baby ideas have changed.

- My career is essentially paused, and will never be the 'main' focus of my week. Instead of working for career development and progression I would be working because we financially require it.

3. I've had to make adjustments in my hours or job duties which have had major career implications.

The need to realign job responsibilities was a prevailing theme among many of this study's respondents. The following are typical responses:

- Working part-time rather than full-time. Less ability to commit to major projects and out of hours - committees, conferences, interstate or overseas.

- I was in one role which I enjoyed but it is unlikely management will allow me to return to that role. I will be given a different role at the same level with part-time hours. 
- Don't work enough hours to increase skill knowledge and practice to go up a level of responsibility on pay.

- I don't work shift work while kids are young therefore I moved to an office hours out of nursing.

- Increased time to complete supervisory period to gain clinical psychologist title due to reduced hours. Reduced opportunity for project work, long-term clients, generally viewed as 'temporary' staff whilst pregnant.

- It's difficult to pursue a career as a senior physio on a ward part-time.

- I am staying casual to be able to care for my daughter and work the hours that suit my family life.

\section{Childcare options are important to me.}

Another major concern for many of the participants was the need to find childcare and whether or not to use non-family members as caregivers. Here are a few examples:

- How on earth can a mother leave her baby after 6 months? Unfortunately, though in these expensive times we are forced to. I look forward to advancing my nursing career once my family is more independent. Until then my baby is number one. It will be a shame to lose my $\mathrm{CN}$ position (must work 20 hours/week to maintain) but my family is more important at the moment.

- Biological clock ticked, could not delay child bearing, I decided that child care per babies was unacceptable to me (concerns about attachment emotional development and physical 
health) and breastfeeding is a priority. So I have had a prolonged leave and have stayed at lower level of qualifications/employment because of this.

- As a single mother I have to put my son into day-care for four days per week, which will be difficult but financially necessary.

- In order to continue to work I had to take my child to day-care, which is something I would have preferred not to do. If my family was here I could have worked more hours without feeling guilty of allowing strangers (day-care) to raise my child.

5. I have reduced educational opportunities as a result of family responsibilities.

Participants frequently commented on their delayed or permanently-impacted options for additional education for purposes of skills enhancement and/or career progression. Kaplan et. al theorized that the career anchors of nurses are partly determined by the academic levels they have achieved. ${ }^{23}$ Sample comments from the current study follow:

- I left several projects unfinished to have my baby and quit my doctoral studies.

- Meaning? I gave up study to have a baby.

- Gave up studying a law degree to look after my kids.

- I have not pursued courses of further education or programs.

- Lose ability to do study days and keep up to date with advances. Clinical skills drop off as does confidence. So more likely to not pursue career change or advancement.

\section{I can't juggle it all.}

Many participants were clearly frustrated with their personal inability to juggle both child rearing 
and full participation in their careers. Other participants commented that they had been disappointed in their employers' support for them after the birth of their children.

- It is impossible to do both without trade-offs. Time at work is time away from family and vice-versa.

- It is really difficult to juggle all the hats of mother, wife, friend, employee etc. Returning to work will affect my individual personal time and my ability to have time to exercise.

- Missed promotion, missed training, less independent due to loss of income.

- I think it is impossible to have both family and career needs met at the same time, despite society's expectations of this.

- Was told by staff in higher positions that pretty much I would have to choose between motherhood or a career if I wanted to advance from current position even though I am fully qualified to do so.

- I can't work full-time in a senior position as these are only allocated to fulltimers.

\section{I can have it all.}

It's worth noting that a few of the current study participants had not experienced the juggling act dilemma described above. They believed that a satisfactory work and family balance was difficult but achievable.

- I will still have my same position as before I had child number one and have been supported in the commencement of further studies to achieve a management position by 
my manager on return from parental leave after child 2 which will continue on return from leave after child three.

- I believe mums have a very valuable role to play in the workforce. The people skills learnt from raising children are invaluable. Women who choose to have children in their twenties and early 30's have the ability to be leaders in their 40's and 50's when their children are more independent. I have had no problems or barriers to returning to work after maternity leave. The only issue has been trying to find a balance between work and home and have found by working night shifts I see my children more.

In relation to this it can be noted that while the majority of respondents in our study, $59 \%$, indicated that they had made a trade-off between family and career, just over $39 \%$ indicating that they had not had to make a trade-off. Doctors at $80 \%$ and other health professionals at $62 \%$ were more likely to recognize a trade-off than nurses at 54\%. Just under half of those in each of these groups who perceived a trade-off had anticipated making this trade-off. However, the data indicate that there is strong commitment to their profession from the bulk of respondents. This commitment results from enthusiasm for, and enjoyment of, their profession along with feelings of pride and self image invested in their profession.

Respondents in the current study were also asked whether, if they were assured of a reasonable income without having to work, would they still prefer to have a paid job, or would not bother to do so. Almost three quarters of respondents $(72.3 \%)$ indicated they would still choose to work. Doctors, $(87 \%)$ were most likely to do so while nurses $(67 \%)$ were least likely to. Doctors were 
also much more likely to be either the main income earner or joint income earner $(67 \%)$, whereas for nurses and other health professionals the spouse, at over $60 \%$, was the main income earner.

\section{Policy Implications}

Understanding women's non-monetary motivators is essential for determining effective approaches to employee rewards and career development in the future. ${ }^{37}$

The importance of the Lifestyle career anchor has been supported by this study of mothers on maternity leave in the health professions. This predominance of lifestyle needs is especially critical for hard-to-hire professions, such as nursing and other healthcare professionals. We found that the majority of our respondents still want a satisfying career despite early motherhood demands. Some women felt they had given up career and higher education aspirations despite their continuing interest in growing professionally. Insightful organizations would facilitate their continuing education as a way of accessing talented professionals as well as providing alternative work schedules and other workplace flexibilities to enable the still-dedicated mothers to continue their contributions to the organization.

Childcare and breastfeeding are crucial issues for this population and the organization that wishes to be most competitive for the most talented healthcare professionals will seek ways to offer these alternatives. 


\section{References}

1. Schein EH. Career dynamics: matching individual and organizational needs. Reading (MA): Addison-Wesley; 1978.

2. Schein EH. Career survival: strategic job/role planning. San Diego (CA): Pfeiffer \& Company; 1993.

3. Schein EH. Career anchors revisited: implications for career development in the twenty-first century. Acad Manag Exec. 1996;10(4):80-89.

4. Nowak M, Thomas G. Employment directions of Curtin School of Nursing and Midwifery graduates 2004 and 2006: a report for the School of Nursing and Midwifery, Curtin University of Technology. Perth: Graduate School of Business, Curtin University of Technology; 2008.

5. Dockery AM, Barns A. Who'd be a nurse? Some evidence on career choice in Australia. Aust Bull Lab. 2005;31(4):350-383.

6. Schein EH. Career anchors: discovering your real values. San Diego (CA): Pfeiffer \& Company; 1990.

7. Fiorentine R. Increasing similarity in the values and life plans of male and female college students? Evidence and implications. Sex Roles. 1988;18:143-158.

8. Preston A. An empirical analysis of the career expectations of women in science and technology courses. Lab Ind. 2006;16(3):21-38.

9. Chapman B, Dunlop Y, Gray M, Liu A, Mitchell D. The impact of children on the lifetime earnings of Australian women: evidence from the 1990s. Aust Econ Rev. 2001; 34(4):373-389.

10. Breusch T, Gray E. New estimates of mother's forgone earnings using HILDA data. Aust J Lab Econ. 2004;7(2):125-150.

11. Loughran DS, Zissimopoulos JM. Why wait? The effect of marriage and childbearing on the wages of men and women. J Hum Resour. 2009;44(2):326-349.

12. Napari S. Is there a motherhood wage penalty in the Finnish private sector? Labour. 2010; 24(1):55-73.

13. Cabrera E. Opting out and opting in: understanding the complexities of women's career transitions. Career Dev Int. 2006;12(3):218-237.

14. Carney T. The employment disadvantage of mothers: evidence for systemic discrimination. $\mathbf{J}$ Ind Relat. 2009;51(1):113-130.

15. Schein EH Career anchors and career paths: a panel study of management school graduates. Cambridge (MA): Sloan School of Management, MIT; 1974.

16. Schein EH. How career anchors hold executives to their career paths. Personnel. 1975; 52:11-24.

17. DeLong T. Re-examining the career anchor model. Personnel. 1982;59(3):50-61.

18. Derr B. More about career anchors. In: Derr B, editor. Work, family and the career. New York: Praeger; 1980.p.166-88.

19. Barth T. Career anchor theory. Rev Publ Person Admin. 1993;13(4):27-42.

20. Aune R. The career anchors of selected groups of nurses [dissertation]. University of Utah; 1983.

21. McLees M. The career patterns and orientations of nurses [dissertation]. Edmonton: University of Alberta; 1988.

22. Dellow K. Looking beyond survival: a study of teacher resilience in a context of change [dissertation]. Saskatoon: University of Saskatchewan; 1998.

23. Vanneste J. Schein's career anchor model and its relevance to career satisfaction: a case 
study of engineers at Micro Motors [dissertation]. Minneapolis (MN): Capella University; 2005. 24. Kaplan R, Shmulevitz C, Raviv D (2009) Reaching the top: career anchors and professional development in nursing. Int J Nurs Educ Scholarsh. 2009; 6(1):24.

25. Bonner D. Examining Schein's career anchors in the new workplace: how individual survivors of downsizing perceive their careers [dissertation]. Washington, DC: The George Washington University; 1997.

26. Tladinyane $\mathrm{R}$ The relationship between career anchors and organisational commitment [dissertation]. Pretoria: University of South Africa; 2007.

27. Quesenberry J Career values and motivations: a study of women in the information technology workforce [dissertation]. The Pennsylvania State University; 2007.

28. Pelos S. Career orientations of female entrepreneurs: a study using Schein's career anchor theory [dissertation]. San Francisco (CA): University of San Francisco; 2000.

29. Marshall V, Bonner, D. Career anchors and the effects of downsizing: implications for generations and cultures at work, a preliminary investigation. J Eur Ind Train. 2003;27(6/7):281 91.

30. Ortiz-Morales H. A cultural analysis of Hispanic Registered Nurses' career selections: a quantitative study [dissertation]. Phoenix (AZ): University of Phoenix; 2010.

31. Pemberton C, Herriot P. Cutting through the career jungle. Prof Manag. 1994; Jan:18-19.

32. Perry E. Women in the middle years: assessing internal careers and linkages to work and family [dissertation]. Tulsa (OK): The University of Tulsa; 1993.

33. Konrad A, Ritchie J, Lieb P, Corrigall E. Sex differences and similarities in job attribute preferences: a meta-analysis. Psychol Bull. 2000;126(4):593-641.

34. Australian Bureau of Statistics. Australian Social Trends, December 2010, One for the country: recent trends in fertility. Cat. No. 4102.0. Canberra: ABS; 2010. Available from: www.abs.gov.au/socialtrends.

35. Mukri G. Lifestyle: the career anchor of the 1990s for professional Navy nurses [dissertation]. Washington, DC: The George Washington University; 1999.

36. Jackle M. Contingent employment in nursing: factors affecting career choice [dissertation]. Austin (TX): The University of Texas at Austin; 1993.

37. Yarnall J. Career anchors: results of an organisational study in the UK. Career Dev Int. 1998;3(2):56-61. 
Table 1 Family considerations in career choice

\begin{tabular}{|lcc|}
\hline All Considerations in Career choice & Number & Percentage valid response \\
Potential for family friendly hours & 139 & 49 \\
Ability to combine career and family & 169 & 60 \\
Ease of obtaining employment after child bearing & 124 & 44 \\
Private practice as an option after child bearing & 60 & 73 \\
Potential for part-time work & 206 & 17 \\
Other & 49 & \\
Total response & 283 & \\
\hline
\end{tabular}

Table 2 Career motivation and family

\begin{tabular}{|lcccc|}
\hline & Career motivated & Career motivated & Family more impt. & Family more impt. \\
Response & Frequency & Percent & Frequency & Percent \\
Strongly agree & 13 & 3.4 & 261 & 67.3 \\
Agree & 132 & 34.0 & 113 & 29.3 \\
Neither agree & 131 & 33.8 & 11 & 2.8 \\
nor disagree & & & & - \\
Disagree & 91 & 23.5 & - & 0.3 \\
Strongly & 14 & 3.6 & 1 & \\
disagree & & & & \\
\hline
\end{tabular}

